\title{
A IMPLEMENTAÇÃO ECLESIÁSTICA E O DESENVOLVIMENTO URBANO DA VILA DE SÃO BENTO DO TAMANDUÁ, MINAS GERAIS (1757-1825).
}

Resumo: O artigo apresentado busca compreender o desenvolvimento da malha urbana da vila de São Bento do Tamanduá (atual Itapecerica, Minas Gerais), nos anos iniciais de sua fundação, na transição do século XVIII para o século XIX. Para isso, utiliza-se como foco de análise o processo de implementação eclesiástica ocorrido através da criação da paróquia de São Bento, da criação de associações devocionais leigas e da construção de templos religiosos. A estrutura eclesiástica é assim compreendida como indicativo da dinâmica social ocorrida na fundação das antigas vilas mineiras.

Palavras-chave: São Bento do Tamanduá; Irmandades religiosas; Urbanização.

\section{THE ECCLESIASTICAL IMPLEMENTATION'S PROCESS AND THE URBAN DEVELOPMENT IN SÃO BENTO DO TAMANDUÁ'S VILLAGE, ESTATE OF MINAS GERAIS (1757-1825)}

\begin{abstract}
The presented article aims comprehend the urban development in São Bento do Tamanduá's village (actually Itapecerica, estate of Minas Gerais, Brazil) in the early years of town's foundation, during the transition of eighteenth to nineteenth century. For this, the focus of analysis is centered the ecclesiastical implementation's process, occurred with Saint
\end{abstract}

\footnotetext{
${ }^{*}$ Doutorando em História Social da Cultura pela UFMG com apoio financeiro do CNPq. Mestre em História pela UFSJ.gofhistoria@yahoo.com.br.

\begin{tabular}{l|l|l|l} 
VOL. 3 & N. 5 & JAN/JUN. 2017
\end{tabular}
}




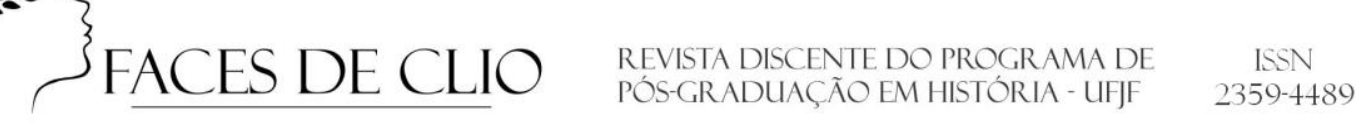

Benedict's parish foundation, the laic religious associations presence and the building of churches. In this way, the ecclesiastical structure is understood as a sample of the social dynamics occurred during the olds' village foundation in Minas Gerais.

Keywords: São Bento do Tamanduá; Religious associations; Urbanization.

"Esta vila é pouco agradável e sua população não é grande"

Desta maneira lacônica, inicia o Bispo da Diocese de Mariana, Dom Frei José da Santíssima Trindade, o relatório final acerca de sua visita pastoral à paróquia de São Bento do Tamanduá, sediada na vila de mesmo nome em 1825. O Bispo, nascido em Portugal, decerto não encontraria, em Tamanduá, suas referências de vila. Distante de Mariana cerca de 50 léguas e da corte do Rio de Janeiro cerca de 80 léguas, Tamanduá fazia parte, àquela época, do começo do fim, ou seja, era a porta de entrada para os limites da recém-criada província de Minas Gerais. Daí para lá, tudo era mais sertão. Caminho obrigatório para quem se dirigia para Goiás e Mato Grosso, Tamanduá era um importante entreposto, formado de uma população heterogênea oriunda de diversas partes da antiga capitania de Minas e do velho Reino, Portugal. Porém, a análise de Dom Frei José não deixa de ser restrita, em alguns aspectos, fruto obviamente de seu lugar social e de seu tempo. A seguir, este artigo busca analisar o processo de implementação eclesiástica ocorrido através da criação de paróquia, de associações religiosas e da construção de templos, como uma espécie de indicativo da proeminência que a localidade passa a conhecer por meio de seu desenvolvimento urbano.

São Bento do Tamanduá passou, em 1789, a constituir-se como sede administrativa de toda uma região há muito ocupada. Com a elevação do arraial à vila de São Bento, culminavase um processo de povoamento iniciado cerca de 50 anos antes, quando por lá chegaram os primeiros aventureiros em busca de ouro. Enquanto foi se consolidando o povoamento da região dos primeiros descobertos auríferos e a fundação das primeiras vilas da capitania de Minas Gerais, muitos desbravadores aventuravam-se a explorar os chamados "sertões", que

\footnotetext{
${ }^{1}$ TRINDADE, Frei José da Santíssima. Visitas Pastorais de Dom Frei José da Santíssima Trindade (1821-1825). Belo Horizonte: Centro de Estudos Históricos e Culturais/Fundação João Pinheiro/IEPHA, 1998. p. 285

\begin{tabular}{l|ll|l} 
VOL. 3 & N. 5 & JAN/UN. 2017
\end{tabular}
}




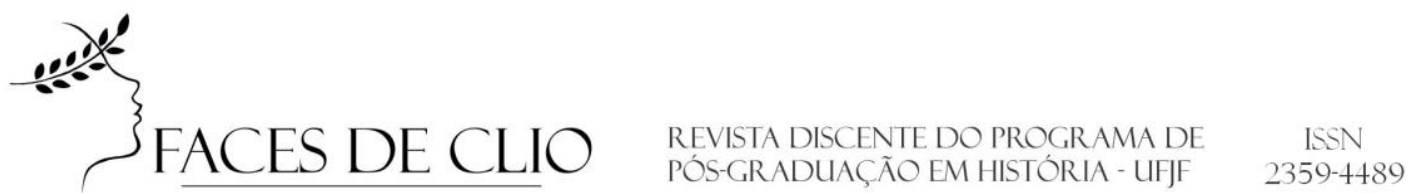

eram as grandes partes desconhecidas e dominadas por povos indígenas ${ }^{2}$. Nas expedições rumo aos sertões do oeste, lograram êxito na descoberta de ouro no ribeirão chamado Tamanduá os sertanistas Estanislau de Toledo Pisa e Feliciano Cardoso de Camargo, que, de acordo com Diogo de Vasconcelos, foram os primeiros moradores da região, que seria “o mais antigo núcleo de povoamento do sertão por este lado"3.

Tamanduá passou então a pertencer ao termo da vila de São José del-Rei, fazendo parte da região administrativa da comarca do Rio das Mortes. A região, apesar de distante dos maiores centros mineradores, prosperou em população e em economia. Habitada por inúmeros fazendeiros, como o Mestre de Campo Inácio Correia Pamplona, o povoamento de Tamanduá auxiliou na empreitada das próximas descobertas e na ampliação das fronteiras da capitania, com o posterior desenvolvimento dos arraiais de Piumhi, Formiga e Bambuí, todos a oeste de Tamanduá. Toda essa região, situada entre as nascentes do rio São Francisco e o curso do rio Grande, era conhecida como sertão do Campo Grande e, segundo Cláudia Damasceno Fonseca, já era há tempos conhecida dos descobridores, o que atrasava o povoamento de toda essa área era o grande número de quilombolas e de índios Caiapós nela existentes e que só foram dominados após inúmeras expedições ${ }^{4}$. A ocupação efetiva da região do Campo Grande pode ser observada através das sucessivas implementações eclesiásticas ocorridas ao longo do século XVIII com a criação de diversas paróquias, o que demonstra a importância dessa região na consolidação das fronteiras da capitania de Minas Gerais, como exemplifica a mesma autora:

[...] o Campo Grande [...] constituiu objeto de cobiça das autoridades eclesiásticas e civis de Goiás nos anos de 1750-1780. Não por acaso, precisamente neste período muitas paróquias foram fundadas pelo bispo mineiro nos "desertos" do oeste: São Bento do Tamanduá (1757), Piuí (1758), Desemboque (por volta de 1761) e Bambuí (1768). As sedes de tais freguesias constituíam verdadeiras "bocas de sertão", situando-se à beira da picada de Goiás e de suas ramificações, abertas a partir de $1736^{5}$.

\footnotetext{
${ }^{2}$ De acordo com Cláudia Damasceno Fonseca, a origem da palavra "sertão" está relacionada às explorações coloniais, e era usada no período como representativo do interior desconhecido e selvagem. Ver FONSECA, Cláudia Damasceno. Arraiais e Vilas D'el Rei - Espaço e Poder nas Minas Setecentistas. Belo Horizonte: Editora UFMG, 2011. p. 51.

${ }^{3}$ VASCONCELOS, Diogo de. História Antiga das Minas Gerais. Rio de Janeiro: Imprensa Nacional, 1948. Vol.1. p. 203.

${ }^{4}$ FONSECA, p. 121.

${ }^{5}$ FONSECA p. 120
}

\begin{tabular}{l|ll|l} 
VOL. 3 & N. 5 & JAN/UN. 2017
\end{tabular} 


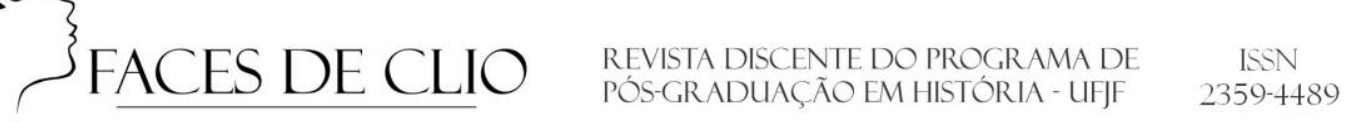

Como visto, o arraial de Tamanduá passou a sediar a paróquia de São Bento em $1757^{6}$, o que, por si só, já é um indicativo da relevância da localidade nesse período, uma vez que o reconhecimento eclesiástico e o título de igreja matriz só eram concedidos a localidades estabilizadas ${ }^{7}$. Tanto é que, em 1782, a paróquia de São Bento do Tamanduá rendia de dízimos 17 mil cruzados, dado que não passou despercebido ao então Pároco de São José del-Rei e futuro inconfidente, Padre Carlos Correia de Toledo, que pretendia transformar a paróquia de São Bento em simples filial de sua igreja matriz, recorrendo para esse fim diretamente à Coroa portuguesa, que lhe atendeu o pedido. Seguiu-se um acontecimento muito curioso: Padre Toledo, indo a Tamanduá com o Juiz Ordinário de São José, a fim de tomar posse de seus direitos, encontrou no arraial de Tamanduá uma ativa resistência à sua presença, sendo ambos ameaçados de morte. Além disso, como protesto, esconderam as chaves da igreja matriz, impedindo que Padre Toledo ali entrasse. A população mobilizada entrou com recurso junto ao bispado de Mariana, que foi obrigado pela Coroa a resolver a contenda. Tendo o bispado tomado partido de São Bento do Tamanduá, o arraial, ao fim do processo, continuou ostentando seu título de paróquia ${ }^{8}$.

Os primeiros tempos de fundação da paróquia não foram fáceis. Por ser uma área recém-dominada e que, até pouco tempo atrás, encontrava-se em poder de grupos indígenas, o primeiro pároco de Tamanduá, Gaspar Álvares Gondim, em 1757, encontrou por lá apenas uma capela rústica, coberta de palha, a qual ele se empenhou para substituir por um templo melhor e ainda fundou "sete capelas filiais na região, a fim de levar assistência espiritual aos fiéis que

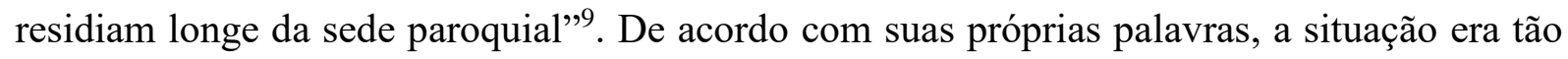
complexa que sua missão seria a de "domesticar os aventureiros"10.

Ao que tudo indica, mesmo após transcorridos mais de 40 anos desde que o Padre Gaspar chegou a Tamanduá, a situação da igreja matriz de São Bento continuava bastante precária. Os irmãos fundadores da arquiconfraria de São Francisco de Assis em Tamanduá

\footnotetext{
${ }^{6}$ A data correta da fundação da Paróquia de São Bento do Tamanduá foi esclarecida em pesquisa realizada por Dom Gil Antônio Moreira como sendo em 15/02/1757; e não 1769 como relatava Diogo de Vasconcelos. Ver: MOREIRA, Dom Gil Antônio. Itapecerica, sua fé sua música: História Eclesiástica de Itapecerica - MG. Belo Horizonte: Imprensa Oficial do Estado de Minas Gerais, 1984. p. 26.

${ }^{7}$ Segundo Cláudia Damasceno "podemos considerar as datas de reconhecimento oficial destes edifícios religiosos como índices indiretos da formação e do desenvolvimento dos núcleos de povoamento”. FONSECA. p. 83.

${ }^{8} \mathrm{O}$ episódio é relatado por MOREIRA, pág. 32; e também por FONSECA, p. 117.

${ }^{9}$ FONSECA, p. 121.

${ }^{10}$ MOREIRA, p. 28
}

\begin{tabular}{l|ll|l} 
VOL. 3 & N. 5 & JAN/UN. 2017
\end{tabular} 


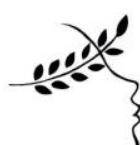

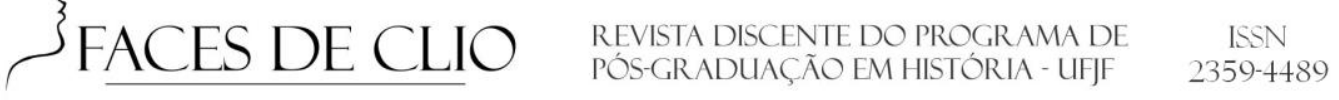

relatam, em 1801, que precisaram construir uma igreja própria devido à "incapacidade da Matriz em que tem o seu altar"11, uma vez que "na dita Vila tem somente a matriz e está [...] bem danificada" 12 . Os confrades de São Francisco concluíram seu templo e a situação decadente da igreja matriz prosseguiu. Em 1825, em visita pastoral, o bispo Dom Frei José da Santíssima Trindade escandalizou-se com a situação da igreja sede de tão importante paróquia:

\begin{abstract}
Vimos a igreja matriz no estado mais deplorável possível e decerto nenhum particular, por mais desleixado que seja, quereria habitar numa casa tão indecente e que nenhuma formalidade mostra de templo em que habita o Homem Deus Sacramentado, e já se vê quanta amargura tem angustiado a nossa alma de vermos o que já nos era patente por informação e até por anúncio geral transmitido pelos passageiros, que se escandalizavam de semelhante indecência, e nenhuma igreja matriz desmembrada de outras há muitos anos, num lugar condecorado com o especioso título de vila e freguesia populosa de fazendeiros ricos, e assim no mesmo estado de alicerce lançado há 40 anos!! ${ }^{13}$
\end{abstract}

Como se sabe, atualmente, a situação crítica da Matriz de São Bento atravessou os séculos, uma vez que, apenas em 1912, o pároco responsável, José dos Santos Cerqueira, conseguiu concluir definitivamente sua reconstrução seguindo as plantas originais ${ }^{14}$.

Mas quem eram os habitantes de Tamanduá na virada do século XVIII para o XIX, quando as principais capelas da vila estavam sendo construídas? Quem eram os aventureiros aos quais se referia o Padre Gaspar Gondim? Infelizmente, não há nenhum recenseamento daquele período, mas algumas fontes, mesmo que tardias, podem oferecer uma pequena amostra da composição de Tamanduá nesse momento em que a vila ganhava proeminência. Um curioso processo presente no arquivo da Arquidiocese de Mariana envolvendo diversas testemunhas em 1805 dá uma ideia de como eram os habitantes da vila 49 anos depois do relato do Pe. Gondim ${ }^{15}$. Tudo aconteceu quando o Pe. Luiz da Silva Mezêncio resolveu cobrar um casamento que havia celebrado à irmã de um tambor de milícia do regimento do Mestre de Campo Inácio Correia Pamplona, chamado Manoel Domingos, que, insatisfeito, atingiu o padre com uma pedrada que lhe quebrou uma costela.

\footnotetext{
${ }^{11}$ AHU. Caixa 168. Doc. 37.

${ }^{12}$ AHU. Caixa 168. Doc. 37.

13 TRINDADE. p. 287.

${ }^{14}$ Para compreensão plena da história da construção da igreja matriz de São Bento, vide MOREIRA, Dom Gil Antônio. Matriz de São Bento - Cem anos de bênçãos. Itu: Ottoni Editora, 2005.

${ }^{15}$ AEAM - Pasta Juízo, doc. 4504. Devassa sobre sacrilégio cometido contra Pe. Mezêncio por Manoel Domingos (pedrada) 1805.
}

\begin{tabular}{l|lll|l} 
VOL. 3 & N. 5 & JAN/JUN. 2017
\end{tabular} 


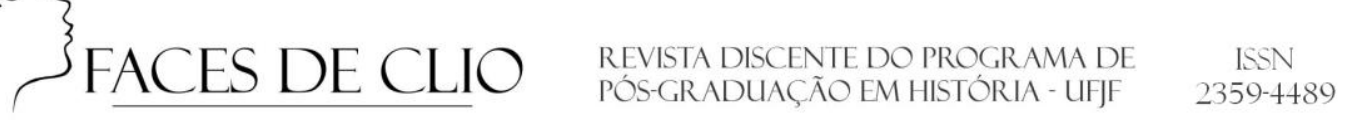

De acordo com uma testemunha, o ferreiro João da Costa Barbosa, de 85 anos (portanto vivo em 1757), natural de Braga, no Reino, viu quando Manoel fugia pelas ruas da vila e, segundo suas próprias palavras, a briga se deu porque o Pe. Mezêncio cobrou de Manoel chamando-o de "larápio", ao que Manoel respondeu "que isso era o mesmo que ser ladrão e que ladrão era o padre" ${ }^{\text {, }}$, e retirou-se. Porém, passado um tempo, retornou e atirou no padre uma pedra de "mais ou menos quatro libras que deixou o padre sem fala" ao que o padre revidou dando uma paulada na cabeça do mesmo Manoel.

Entre as inúmeras pessoas envolvidas na contenda (que parece ter mobilizado todos os principais da vila) é possível observar diversas profissões e procedências, como o reinol João de Araújo, 66 anos, natural do Porto, que ficou escandalizado com o ocorrido que viu de sua casa: "ai que derão hua pedrada no reverendo Mezêncio!" 17; a costureira Alvina Ignácia, de "mais de cinquenta anos" e natural da vila de São José, que morava na casa do padre a distância de "um tiro de pistola"; o músico José Joaquim de Santa Ana, natural de Itabira; o Capitão José Antônio natural de Mariana, entre vários outros. Na tabela abaixo, encontram-se elencadas todas as testemunhas da devassa, na qual é possível analisar melhor a composição da população tamanduense no princípio do século XIX.

\section{TABELA 1}

Relação de testemunhas da devassa sobre sacrilégio cometido contra Pe. Mezêncio por Manoel Domingos $1805{ }^{18}$.

\begin{tabular}{|c|c|c|c|c|}
\hline NOME & COR & NATURALIDADE & PROFISSÃO & IDADE \\
\hline $\begin{array}{c}\text { Capitão João } \\
\text { Caetano de } \\
\text { Almeida Lobo }\end{array}$ & & & & \\
\hline $\begin{array}{c}\text { Pedro Pereira } \\
\text { Ribeiro }\end{array}$ & & & Boticário & \\
\hline $\begin{array}{c}\text { Capitão } \\
\text { Jácomo Lopes } \\
\text { Cardos }\end{array}$ & & Congonhas & $\begin{array}{c}\text { Vive dos } \\
\text { serviços de seus } \\
\text { escravos }\end{array}$ & \\
\hline
\end{tabular}

\footnotetext{
${ }^{16}$ AEAM - Pasta Juízo, doc. 4504.

${ }^{17}$ AEAM - Pasta Juízo, doc. 4504.

${ }^{18}$ Fonte: AEAM: Arquivo Eclesiástico da Arquidiocese de Mariana
}

\begin{tabular}{l|llll} 
VOL. 3 & N. 5 & JAN/JUN. 2017
\end{tabular}




\begin{tabular}{|c|c|c|c|c|}
\hline $\int_{F A}$ & $\mathrm{DE}$ & $\begin{array}{l}\text { REVISTA DISCEN } \\
\text { PÓS-GRADUAÇÃ }\end{array}$ & $\begin{array}{l}\text { EO PROGRAMA DE } \\
\text { EM HISTORIA - UFJF }\end{array}$ & $\begin{array}{c}\text { ISSN } \\
2359-4489\end{array}$ \\
\hline $\begin{array}{l}\text { José Joaquim } \\
\text { de Santa Anna }\end{array}$ & & Itabira & Músico & \\
\hline $\begin{array}{c}\text { João Gonçalves } \\
\text { Matos }\end{array}$ & Pardo & Prados & Carpinteiro & 48 \\
\hline $\begin{array}{c}\text { João da Costa } \\
\text { Barbosa }\end{array}$ & & Braga & Ferreiro & 85 \\
\hline João de Araújo & & $\begin{array}{l}\text { S. Cristóvão do Rio } \\
\text { Tinto, Porto }\end{array}$ & $\begin{array}{l}\text { Vive do trabalho } \\
\text { de seus escravos }\end{array}$ & 66 \\
\hline $\begin{array}{l}\text { Tomaz } \\
\text { Joaquim } \\
\text { Barbosa }\end{array}$ & & Jacuí & $\begin{array}{l}\text { Negócios de } \\
\text { fazenda seca }\end{array}$ & 24 \\
\hline $\begin{array}{c}\text { Antônio } \\
\text { Joaquim da } \\
\text { Costa }\end{array}$ & Pardo & Tamanduá & Ferreiro & 22 \\
\hline $\begin{array}{c}\text { Francisco } \\
\text { Inácio da Terra }\end{array}$ & Branco & Vila de São José & Caixeiro & 23 \\
\hline $\begin{array}{l}\text { Alvina Ignácia } \\
\text { da Silva }\end{array}$ & Parda & Vila de São José & $\begin{array}{c}\text { Vive de seus } \\
\text { fiados de } \\
\text { algodão }\end{array}$ & $>50$ \\
\hline $\begin{array}{c}\text { Simão dos } \\
\text { Santos Ribeiro }\end{array}$ & Branco & Prados & Agricultor & $>50$ \\
\hline $\begin{array}{c}\text { Capitão José } \\
\text { Antônio da } \\
\text { Silva }\end{array}$ & Branco & Mariana & $\begin{array}{l}\text { Vive de fazenda } \\
\text { seca }\end{array}$ & 41 \\
\hline $\begin{array}{c}\text { Filipe Correa } \\
\text { Melo }\end{array}$ & Branco & $\begin{array}{c}\text { Ilha Terceira } \\
\text { (Açores) }\end{array}$ & Caixeiro & 61 \\
\hline $\begin{array}{c}\text { Capitão } \\
\text { Custódio José } \\
\text { da Silva }\end{array}$ & Branco & São Pedro, Porto & $\begin{array}{l}\text { Escrivão dos } \\
\text { órfãos }\end{array}$ & 70 \\
\hline $\begin{array}{c}\text { José Carlos } \\
\text { Dias }\end{array}$ & & São João del-Rei & Fazenda seca & 30 \\
\hline $\begin{array}{c}\text { Joaquim } \\
\text { Ferreira } \\
\text { Carneiro }\end{array}$ & Pardo & Lavras & $\begin{array}{c}\text { Fazenda seca e } \\
\text { molhada }\end{array}$ & 24 \\
\hline $\begin{array}{c}\text { Mariano } \\
\text { Joaquim de } \\
\text { Santana } \\
\end{array}$ & Branco & Barbacena & Vive com o pai & 20 \\
\hline $\begin{array}{c}\text { Jacinto José } \\
\text { Teixeira } \\
\end{array}$ & Branco & Vila de São José & Alfaiate & 22 \\
\hline $\begin{array}{c}\text { Manoel } \\
\text { Rodrigues } \\
\text { Serra } \\
\end{array}$ & Pardo & Mariana & $\begin{array}{c}\text { Sapateiro e } \\
\text { carcereiro da } \\
\text { cadeia }\end{array}$ & \\
\hline $\begin{array}{l}\text { José Barros } \\
\text { Coelho }\end{array}$ & Branco & Pitangui & Agricultor & 50 \\
\hline
\end{tabular}




\begin{tabular}{|c|c|c|c|c|}
\hline$\}_{F A}$ & $\mathrm{DE}$ & $\begin{array}{l}\text { REVISTA DISCEN } \\
\text { PÓS-GRADUAÇÃ }\end{array}$ & $\begin{array}{l}\text { DO PROGRAMA DE } \\
\text { EM HISTÓRIA - UFJF }\end{array}$ & $\begin{array}{c}\text { ISSN } \\
2359-4489\end{array}$ \\
\hline $\begin{array}{c}\text { Thome Mendes } \\
\text { Jardim }\end{array}$ & Branco & Raposos & $\begin{array}{l}\text { Vive de solicitar } \\
\text { causas no juízo } \\
\text { desta vila }\end{array}$ & 69 \\
\hline $\begin{array}{c}\text { Manoel José } \\
\text { Vidigal }\end{array}$ & Branco & Vila de São João & Alfaiate & 25 \\
\hline $\begin{array}{l}\text { Francisco da } \\
\text { Costa Barbosa }\end{array}$ & Pardo & Tamanduá & Ferreiro & 26 \\
\hline $\begin{array}{c}\text { Severino } \\
\text { Muniz Ferreira }\end{array}$ & Pardo & Tamanduá & $\begin{array}{c}\text { Vive de fazer } \\
\text { conduções com } \\
\text { seu carro }\end{array}$ & 33 \\
\hline José da Rocha & Pardo & Caeté & $\begin{array}{l}\text { Vive de seus } \\
\text { negócios de } \\
\text { molhados } \\
\text { varejados } \\
\end{array}$ & 34 \\
\hline $\begin{array}{c}\text { José Gonçalves } \\
\text { Gomide }\end{array}$ & Branco & $\begin{array}{l}\text { Desterro (termo de } \\
\text { Tamanduá) }\end{array}$ & Alfaiate & 31 \\
\hline José Francisco & Pardo & Vila Rica & $\begin{array}{l}\text { Laetoeiro } \\
\text { [latoeiro] }\end{array}$ & 40 \\
\hline
\end{tabular}

Os dados dessa tabela, apesar de abrangerem apenas uma pequena parte da população da vila, são úteis como base de referência para começar a compreender como se formava uma parcela de população, qual era sua origem, em quais atividades econômicas se envolviam e qual era sua faixa etária. A princípio, fica claro na relação de testemunhas a presença de profissionais diversos. A maioria compõe-se de comerciantes e prestadores de serviço. Duas testemunhas eram envolvidas com o aparelho administrativo da vila e apenas uma testemunha trabalhava com ofício artístico, nesse caso, músico.

Nota-se que, nesse levantamento, a maioria dos moradores provinha da região da comarca do Rio das Mortes, seguidos pelos oriundos da comarca do Rio das Velhas e pelos reinóis. Observam-se, também, cinco provenientes do termo da Vila de São José (especificamente de São José e Prados), a antiga sede administrativa de Tamanduá. Através dos dados apresentados por Cláudia Damasceno Fonseca relativos ao número de fogos ${ }^{19}$ de 1830 , é possível notar que Tamanduá contava com 180 fogos contra 158 da Vila de São José ${ }^{20}$. Porém esses dados referem-se apenas ao número de habitações existentes na vila, e não em todo termo, que englobava todos os arraiais e fazendas anexados à administração da vila. Com relação aos

\footnotetext{
${ }^{19}$ Fogos era a denominação utilizada para se referir ao número de habitações construídas, sendo o fogo, o baluarte das casas do período. FONSECA, p. 378.

${ }^{20}$ FONSECA, p. 379

\begin{tabular}{l|lll} 
VOL. 3 & N. 5 & JAN/JUN. 2017
\end{tabular}
} 


\section{$\left\{\begin{array}{ll}\text { FACES DE CLIO } \\ \text { REVISTA DISCENTE DO PROGRAMA DE } \\ \text { PÓGRADUAÇÃO EM HISTORIA-UFJF }\end{array} \begin{array}{l}\text { ISSN } \\ 2359-4489\end{array}\right.$}

dados de todo termo, é interessante reproduzir aqui a tabela apresentada por Cláudia Damasceno, comparando os Concelhos (área de abrangência da administração das vilas) de Tamanduá, Vila Rica e São José:

TABELA 221

Concelhos: comparação entre o número total de habitantes (incluindo escravos), o número de fogos dos termos, das freguesias urbanas e das sedes do início do século XIX.

\begin{tabular}{|c|c|c|c|c|c|}
\hline CONCELHO & $\begin{array}{c}\text { Número de } \\
\text { habitantes } \\
\text { TERMO } \\
\mathbf{( 1 8 0 8 )}\end{array}$ & $\begin{array}{c}\text { Número de } \\
\text { fogos } \\
\text { TERMO } \\
\mathbf{( 1 8 1 0 -} \\
\mathbf{1 8 1 5 )}\end{array}$ & $\begin{array}{c}\text { Número de } \\
\text { habitantes } \\
\text { por fogo no } \\
\text { TERMO }\end{array}$ & $\begin{array}{c}\text { Número de } \\
\text { fogos na } \\
\text { freguesia } \\
\text { da sede } \\
\mathbf{( 1 8 1 0 -} \\
\mathbf{1 8 1 5}\end{array}$ & $\begin{array}{c}\text { Número de } \\
\text { fogos VILA } \\
\mathbf{( 1 8 3 0 )}\end{array}$ \\
\hline VILA RICA & 22.222 & 3.333 & 6.66 & 1.801 & 1.206 \\
\hline $\begin{array}{c}\text { VILA DE } \\
\text { SÃO JOSÉ }\end{array}$ & 21.448 & 2.795 & 7,67 & 430 & 158 \\
\hline $\begin{array}{c}\text { VILA DE S. } \\
\text { B. DO } \\
\text { TAMANDUÁ }\end{array}$ & 16.030 & 2.174 & 7,37 & 1.860 & 180 \\
\hline
\end{tabular}

Cabe notar que uma freguesia dizia respeito à área de abrangência da paróquia, enquanto o termo representava a abrangência do senado das câmaras. Desse modo, percebem-se diferentes níveis de urbanização: comparadas à Vila Rica, capital da capitania de Minas, São José e São Bento do Tamanduá tinham, respectivamente, 5,7 \% e 14,5\% dos fogos situados na vila. Além disso, o termo de ambas abrangia uma região bem mais ampla do que o de Vila Rica que concentrava $36,2 \%$ de seus fogos na vila. O baixo número de habitações em São Bento do Tamanduá não passou despercebido a um contemporâneo, Diogo Pereira Ribeiro de Vasconcelos, que, em sua "Breve descrição geográfica, física e política da capitania de Minas Gerais", relata o que considera uma ambiguidade:

Cumpre notar que sendo seu termo composto de fazendas de agricultura e de criar, de uma prodigiosa fertilidade e produção, a vila não lhe responde. Tão erma de edifícios como de gente, a renda da câmara em o ano de 1806 mal chegou [a] $332 \$ 000$ réis $^{22}$.

\footnotetext{
${ }^{21}$ Tabela reproduzida a partir da tabela 8.4 de FONSECA, p. 385

${ }^{22}$ VASCONCELOS, Diogo Pereira Ribeiro de. Breve descrição geográfica, física e política da capitania de Minas Gerais. Belo Horizonte: Centro de Estudos Históricos e Culturais/Fundação João Pinheiro, 1994. p. 142.
} 


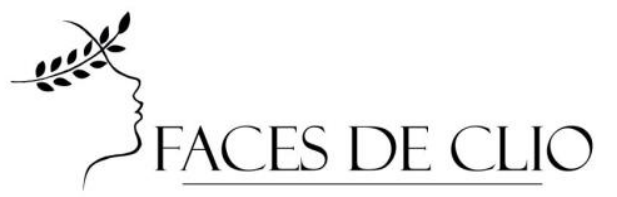

Mas o português previa para Tamanduá um futuro promissor, quando, no mesmo relato destacava que "a vila de São Bento do Tamanduá [...] promete ser uma das melhores da província"23. A contradição entre abundância de recursos e pouca urbanização também chamou a atenção do famoso viajante francês Saint-Hilaire, que por lá passou, em 1819, a caminho da nascente do rio São Francisco. De acordo com ele, os moradores de Tamanduá eram:

[...] em sua maioria agricultores que só vão à cidade aos domingos e nos dias de festa. Há também alguns negociantes e trabalhadores comuns, além dos indigentes, que se aproveitam da abundância existente na região para pedir comida ora numa casa, ora noutra, e passam a vida na ociosidade ${ }^{24}$.

É interessante também reproduzir aqui a descrição que faz Saint-Hilaire da vila, uma vez que seu olhar estrangeiro abrange aspectos normalmente não encontrados na documentação contemporânea. Segundo suas palavras:

A cidade ${ }^{25}$ está situada num vale e é rodeada de morros bastante elevados e cobertos de matas. Suas ruas são inteiramente irregulares, cheias de pedras e ladeiras. As casas são geralmente isoladas umas das outras e cercadas por muros, tendo algumas uma aparência bastante bonita. Não obstante, quando se contempla a cidade de um ponto mais elevado a sua própria irregularidade produz um efeito muito agradável na paisagem. No seu conjunto, a cidade oferece um belo contraste contra o verde sombrio das matas que a rodeiam de todos os lados, não somente devido à brancura das paredes de suas casas e ao colorido dos telhados, mas também, e em especial, por causa da posição das casas, que parecem lançadas no meio das massas de verdura formadas pelas bananeiras e laranjeiras que enchem os seus quintais ${ }^{26}$.

"Massas de verdura, belo contraste contra o verde, brancura das paredes..." Saint-Hilaire compõe seu relato da vila de São Bento da mesma forma como um pintor retrataria uma paisagem em um quadro. Sua descrição, mais pitoresca do que as demais citadas, confere a Tamanduá um certo ar bucólico da urbe em harmonia com o ambiente ao redor, características decerto não prioritárias aos habitantes daquele momento. Mas cabe lembrar que esses relatos

\footnotetext{
${ }^{23}$ VASCONCELOS, Diogo Pereira Ribeiro de. Breve descrição geográfica, fisicica e politica da capitania de Minas Gerais. Belo Horizonte: Centro de Estudos Históricos e Culturais/Fundação João Pinheiro, 1994. p. 84

${ }^{24}$ SAINT-HILAIRE, Auguste de. Viagem às nascentes do Rio São Francisco. Belo Horizonte: Ed. Itatiaia, 2004. p. 86

${ }^{25}$ Nota-se que São Bento do Tamanduá não ostentava neste período o título de cidade, o equívoco origina-se possivelmente pela tradução do termo francês ville, comumente traduzido para o português como cidade.

${ }^{26}$ SAINT-HILAIRE. p. 88
}

\begin{tabular}{l|lll|l} 
VOL. 3 & N. 5 & JAN/JUN. 2017
\end{tabular}




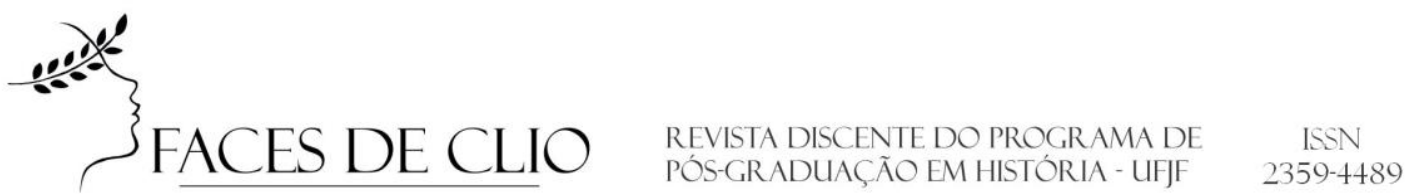

foram reorganizados para um público leitor europeu, que, provavelmente, não realizavam viagens a países tão distantes e que tinham, no relato viajante, uma narrativa de aventura ${ }^{27}$.

O nível de urbanização dos arraiais mineiros, no princípio do século XIX, pode ser mensurado através do número de fogos, pelas implementações administrativas e através das construções religiosas. Como se sabe, em Minas Gerais, deve-se, principalmente, às irmandades religiosas leigas a construção e ornamentação dos templos. Mesmo as igrejas matrizes que, a rigor, deveriam ser mantidas com recursos públicos, muitas vezes, ficavam a cargo das irmandades do Santíssimo Sacramento, que eram as responsáveis pela manutenção desses templos. A proliferação de irmandades religiosas, em vários arraiais e vilas mineiros, acabava por prejudicar a manutenção das igrejas matrizes. Nos vários relatos de visitas pastorais feitos pelo bispo da Diocese de Mariana, Dom Frei José da Santíssima Trindade, pelo território mineiro entre 1821 e 1825, é recorrente em sua fala a situação "indecente" de inúmeras matrizes que se encontravam em péssimo estado de conservação ${ }^{28}$. Relatou-se, anteriormente, a situação crítica da igreja matriz de São Bento do Tamanduá, que passou parte do século XIX em um estado “deplorável”, como nos relatou o bispo em $1825{ }^{29}$.

Enquanto a matriz de São Bento estava em condições críticas no começo do século XIX, as demais igrejas da vila de São Bento do Tamanduá já estavam em sua maioria, edificadas. Isso foi relevante para desenvolvimento do lugarejo, uma vez que nos dizeres de Cláudia Damasceno Fonseca,

O número, o tamanho e a qualidade arquitetônica dos edifícios religiosos dão a medida da riqueza das irmandades, além de sugerir a existência de uma cultura artística relativamente desenvolvida. Como se sabe, a emulação entre as diferentes associações religiosas, bem como as rigorosas normas eclesiásticas referentes aos lugares e aos objetos do culto conduziram a um notável desenvolvimento dos ofícios ligados à arte e à arquitetura em Minas Gerais, sobretudo na segunda metade do século XVIII. Também podemos considerar que o grau de sociabilidade das populações é proporcional ao desenvolvimento de tais organismos associativos: a multiplicação de confrarias se traduz pelo aumento do número de celebrações e festas religiosas, das

\footnotetext{
${ }^{27}$ De acordo com Guiomar de Grammont: “os ‘países exóticos', como eram então chamadas as colônias, exerciam uma enorme atração no público leitor europeu. As elites dominantes tinham a oportunidade de comprovar 'ao vivo' esse exotismo. Outros, de menos poder aquisitivo, ou não podendo ou não querendo viajar, liam as façanhas nos livros de viagem. Essa é, sem dúvida, uma das explicações para o grande sucesso desse tipo de obra publicada na Europa do século XIX.” In: GRAMMONT, Guiomar de. Aleijadinho e o aeroplano. Rio de Janeiro: Civilização Brasileira, 2008. p. 134.

${ }^{28}$ TRINDADE, Frei José da Santíssima. Visitas Pastorais de Dom Frei José da Santíssima Trindade (1821-1825). Belo Horizonte: Centro de Estudos Históricos e Culturais/Fundação João Pinheiro/IEPHA,1998.

${ }^{29}$ TRINDADE. p. 287.
}

\begin{tabular}{l|ll|l} 
VOL. 3 & N. 5 & JAN/UN. 2017
\end{tabular}




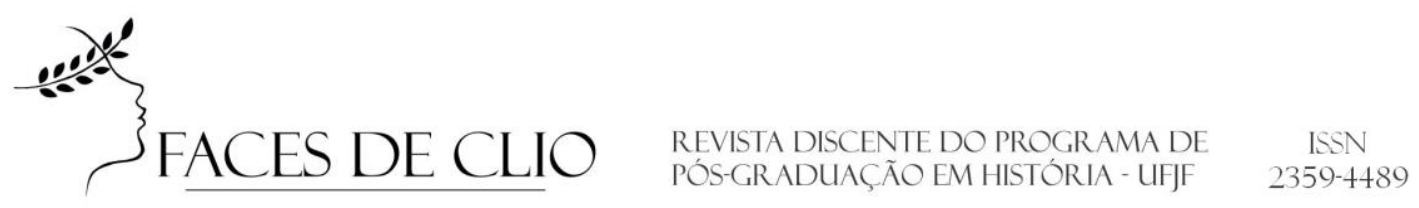

quais tomavam parte não apenas os habitantes das vilas e arraiais, mas também a população dos arredores rurais ${ }^{30}$.

No período da passagem de Dom Frei José por Tamanduá, em 1825, as únicas irmandades que se podem atestar com segurança a existência são a arquiconfraria de São Francisco (1800) e a de Nossa Senhora do Rosário dos Homens Pretos, de $1818^{31}$. Com relação à arquiconfraria de São Francisco, a datação é clara, havendo, não apenas no Livro de Compromisso, mas também no processo de confirmação do mesmo pela Mesa de Consciência e Ordens de Lisboa, a confirmação da existência da referida arquiconfraria ${ }^{32}$. Além do mais, o templo sede edificado por essa Arquiconfraria, a capela de Santo Antônio e São Francisco, permanece edificado.

Já no que diz respeito à irmandade do Rosário, existe apenas uma ata de fundação dessa associação, em 1818, identificada em pesquisa de mestrado de Melina Teixeira Souza ${ }^{33}$, sem que se saiba ao certo qual período de atuação da mesma, uma vez que a documentação, porventura produzida por essa irmandade, não foi localizada. Se essa irmandade buscou um registro oficial para legalizar sua existência, esse documento não deixou rastros. A irmandade também não foi identificada na minuciosa pesquisa realizada por Caio Cesar Boschi ${ }^{34}$ sobre as associações religiosas leigas em Minas Gerais no século XVIII, talvez devido à situação lacunar das fontes conforme já mencionado.

Todavia, a capela sede da irmandade de Nossa Senhora do Rosário não só foi construída como sobrevive até hoje. Ainda, de acordo com o mesmo documento, identificado por Melina Teixeira, a licença para utilização desse templo foi concedida em 1815, sendo, possivelmente, sua construção anterior a essa data, sem que se possa precisar exatamente em que ano. O Bispo de Mariana, Dom Frei José da Santíssima Trindade, também relata o estado dessa igreja em sua visita pastoral feita a Tamanduá, em 4 de setembro de 1825:

\footnotetext{
${ }^{30}$ FONSECA. p.399.

${ }^{31}$ Data identificada pela pesquisa inédita de: SOUZA, Melina Teixeira. O reinado de Itapecerica no século XX : distintos sentidos de tradição. Dissertação (Mestrado em História). UFOP, 2012. 209f.

${ }^{32}$ AHU. Caixa 168 Doc. 37. APSB. Livro de Compromisso da Arquiconfraria de São Francisco e Santo Antônio da Vila de São Bento do Tamanduá.

${ }^{33}$ A ata, em poder de uma organização particular, foi mapeada por SOUZA, Melina Teixeira. O reinado de Itapecerica no século XX: distintos sentidos de tradição. Dissertação (Mestrado em História). UFOP, 2012. 209f. ${ }^{34}$ BOSCHI, Caio César. Os leigos e o poder (Irmandades Leigas e Politica Colonizadora em Minas Gerais). São Paulo: Editora Ática, 1986.
}

\begin{tabular}{l|lll} 
VOL. 3 & N. 5 & JAN/JUN. 2017
\end{tabular}




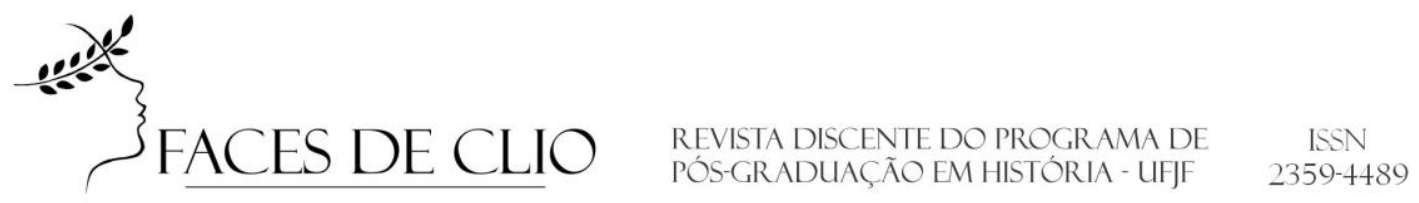

A capela de Nossa Senhora do Rosário, toda de pedra, com adro seguro por muros da mesma pedra, mas não tem forro nem pavimento, e só um altar com um arco de madeira pintado de branco onde, sobre alguns degraus, tem a imagem de Nossa Senhora $^{35}$.

Essa descrição pouco corresponde ao estado da Igreja do Rosário atualmente, isso porque o antigo adro foi demolido, e a fachada da capela, reconstruída em 1917 em estilo eclético, devido a um raio que destruiu o frontispício original ${ }^{36}$.

Além da capela de Nossa Senhora do Rosário, já se encontrava edificada, nesse mesmo período, a capela de Nossa Senhora das Mercês. As condições de construção desse templo permanecem incógnitas, uma vez que não foi identificado até o momento nenhum documento referente a essa capela ou a uma possível irmandade que possa ter abrigado. Contudo, é plausível supor que, em algum momento do século XVIII, essa irmandade tenha existido, mesmo sem reconhecimento legal, pois nada, além de uma devoção mútua a Nossa Senhora das Mercês, explicaria a existência de uma capela das Mercês em Tamanduá. Dom Frei José, no mesmo relato, afirma estar a capela das Mercês "arruinada e quase sem uso" 37 . Sua descrição deixa entrever que a capela já era antiga em 1825, já que naquela data já estava "arruinada", sendo possível supor que sua construção remonte ao século XVIII. Além disso, se houve em São Bento do Tamanduá uma irmandade das Mercês, aparentemente, a mesma não existia mais em 1825, por razões desconhecidas.

Têm-se ainda as desaparecidas capelas de São Miguel e de Santa Rita, edificações demolidas nos anos 1930, das quais sobraram apenas registros fotográficos. A datação de ambas tampouco se sabe, porém, suas características arquitetônicas são condizentes com as demais capelas remanescentes. Como se pode observar, com exceção da matriz de São Bento e da capela das Mercês (cuja datação não se sabe), as demais capelas são aparentemente contemporâneas, variando em poucos anos sua edificação. Coincidentemente, esse período corresponde aos anos iniciais da fundação da vila, ocorrida em 1789. Nota-se que a construção de igrejas é um indicativo do desenvolvimento da malha urbana de Tamanduá.

Com relação às demais capelas, exceto a matriz, não se pode ainda informar qual papel exerceram nesse aspecto. Entretanto, sobre a igreja de Santo Antônio e São Francisco, sabe-se

\footnotetext{
${ }^{35}$ TRINDADE. p. 286.

${ }^{36}$ MOREIRA, Dom Gil Antônio. Matriz de São Bento - Cem anos de Bençãos. Itu: Ottoni Editora, 2005. p. 149.

${ }^{37}$ TRINDADE, p. 286.
} \begin{tabular}{l|llll} 
VOL. 3 & N. 5 & JAN/JUN. 2017
\end{tabular} 


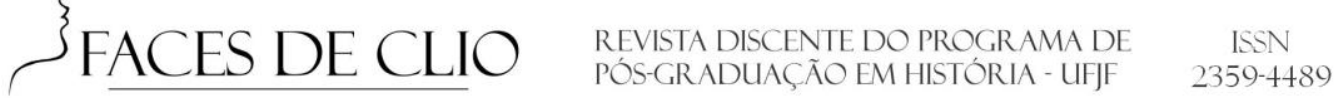

que sua construção esteve imbricada no processo de desenvolvimento do antigo arraial. Nos requerimentos remetidos a Lisboa por Antônio Tristão Barbosa, fundador da Arquiconfraria de São Francisco em Tamanduá, nota-se que a construção da igreja envolveu não apenas questões religiosas, mas também problemas administrativos da recém-criada vila de São Bento do Tamanduá. Além de solicitar a confirmação dos estatutos da arquiconfraria, Antônio Tristão Barbosa fez mais sete requerimentos a Sua Alteza Real, os quais vêm aqui elencados:

1) Pedido de doação de um terreno, denominado pântano, que de acordo com o documento, "por dívida do guarda-mor Manoel Reis Gondim, ficara pertencendo a Fazenda Real" ${ }^{38}$;

2) Que se criasse em São Bento do Tamanduá um cargo de juiz de fora, de acordo com Antônio Tristão Barbosa;

Para melhor administração da justiça contra as prepotências que ali praticam principalmente no tempo das correições, Francisco José Pereira e sua mulher, Domingos Reis Gondim, Francisco da Costa Oliveira, mesmo os oficiais de justiça daquela Vila ${ }^{39}$.

3) Pedido de concessão do uso de um moinho d'água para "sustentação e despesas da Confraria" 40 ;

4) Pedido de escritura de doação de escravos doados ao patrimônio da arquiconfraria;

5) Reparação do custo de "vários danos da mortandade que fizeram em gado pertencente a Confraria" ${ }^{41}$, e também a restituição de terras "que lhe tem sido usurpadas" $" 42$;

6) O provimento de uma "cadeira" de gramática para o vice-comissário da arquiconfraria, Padre Braz Vicente da Silva, para que, tendo ele um "ordenado de professor régio" ${ }^{43}$, possa se manter como comissário da arquiconfraria, para que, dessa

\footnotetext{
${ }^{38}$ AHU - Caixa 168 Doc. 37.

${ }^{39}$ AHU - Caixa 168 Doc. 37.

${ }^{40}$ AHU - Caixa 168 Doc. 37.

${ }^{41}$ AHU - Caixa 168 Doc. 37.

${ }^{42}$ AHU - Caixa 168 Doc. 37.

${ }^{43}$ AHU - Caixa 168 Doc. 37.
}

\begin{tabular}{l|ll|l} 
VOL. 3 & N.5 & JAN/JUN. 2017
\end{tabular} 


\section{$\left\{\right.$ FACES DE CLIO $\begin{array}{l}\text { REVISTA DISCENTE DO PROGRAMA DE } \\ \text { PÓS-GRADUAC̃̃O EM HISTÓRIA - UFIF }\end{array}$}

maneira, não tenha a mesma que lhe pagar ordenados, podendo, dessa forma, aplicar o dinheiro das côngruas "a cura dos enfermos"44 do hospital da arquiconfraria;

7) Por último, Antônio Tristão pede que o senado da câmara de Tamanduá concorra com a metade do valor necessário para a "fatura da ponte" 45 , pois, para se chegar à igreja de Santo Antônio, até hoje, é necessário atravessar o rio Vermelho, que divide a antiga vila de São Bento; além disso, o arquiconfrade pede ainda "que se alinhem as ruas da Vila concorrendo os particulares nas suas Testadas" ${ }^{\prime 6}$, obra que em suas palavras era "de muita precisão e necessidade" 4 .

Com exceção da confirmação dos estatutos da arquiconfraria, todos os demais sete pedidos de Antônio Tristão Barbosa foram veementemente rejeitados pelo conselho ultramarino, que alegava o seguinte:

Todas estas individuais pertenções [sic] entre si são diversas ainda que tendentes do mesmo fim, tem os ordinários meios da lei que expressamente exclui o meio de conhecimento extraordinário; não são deferíveis nem o poderão ser sem constar da justiça delas por informações que devem proceder, ouvidos os terceiros acusados, implicados nos ditos requerimentos. 48

Pode-se observar, então, que quando ocorreu a construção da igreja de Santo Antônio, o desenvolvimento urbano de Tamanduá ainda caminhava a passos lentos. Não se sabe, por exemplo, qual foi a reação do senado da câmara de São Bento do Tamanduá aos requerimentos de Antônio Tristão Barbosa nem qual relação este tinha com o aparelho administrativo da vila. Porém, nota-se que nem sempre era uma relação pacífica. Antônio Tristão denuncia no item 2 o que parecem ser irregularidades não especificadas, as quais chama de "prepotências", cometidas por uma série de pessoas e, até mesmo pelos “oficiais de justiça daquela Vila”. Nesse mesmo período, por volta de 1802, os sertões do Rio Grande, próximos a Tamanduá, abrigavam diversos foragidos, segundo mostra uma pesquisa de Carla Maria Junho Anastasia:

\footnotetext{
${ }^{44}$ AHU - Caixa 168 Doc. 37.

${ }^{45}$ AHU - Caixa 168 Doc. 37.

${ }^{46}$ AHU - Caixa 168 Doc. 37. Dava-se o nome de 'testada' às fachadas das casas. CAMPOS, Adalgisa Arantes. Introdução ao barroco mineiro. Belo Horizonte: Crisálida, 2006. p. 20.

${ }^{47}$ AHU - Caixa 168 Doc. 37.

${ }^{48}$ AHU - Caixa 168 Doc. 37.
}

\begin{tabular}{l|llll} 
VOL. 3 & N.5 & JAN/JUN. 2017
\end{tabular} 


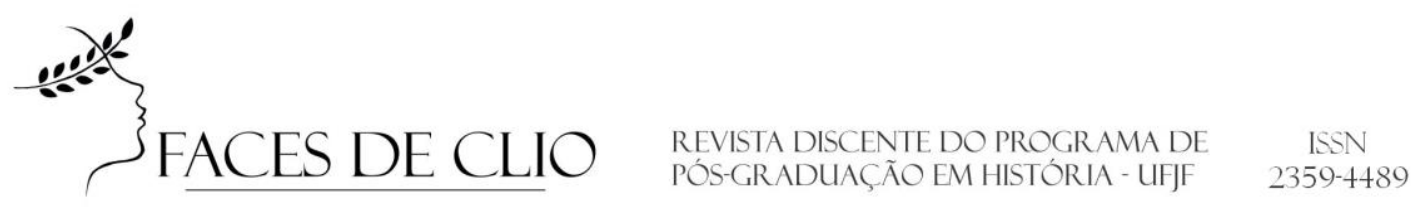

Em 1802, os oficiais da câmara de São Bento do Tamanduá afirmavam que a vila e o seu termo faziam vizinhança de uma multidão de assassinos que, refugiados pelos atrozes e desumanos delitos cometidos por várias partes desta capitania, tem feito afronta e morada nos sertões das margens do Rio Grande, que dividia o termo de Tamanduá com o da vila de Campanha da Princesa. Os oficiais da câmara referiamse especificamente a Januário Garcia Leal e sua quadrilha [...] Além de não respeitar a justiça, Januário, juntamente com seu tio Matheus Luís Garcia, foi a casa do juiz ordinário, ambos armados de baionetas, pistolas e facas para o agredirem [grifo da autora $]^{49}$.

Esse episódio relatado por Anastasia demonstra que Tamanduá ainda caminhava no desenvolvimento de sua autoridade camareira. Um termo extremamente grande e ainda pouco fiscalizado acabava por esconder criminosos em suas matas. Relevante nesse ponto é a preocupação de Antônio Tristão Barbosa nessas questões, já que seu requerimento não fala especificamente de violência, e sim de "prepotências cometidas" que remontam também a episódios de corrupção dos oficiais de justiça. Mas é visível como as questões se imbricavam: não se tratava apenas da construção de uma igreja, e sim da construção de uma sociedade, de um processo de civilização.

Dada à característica do governo português de transferir atribuições às associações religiosas $^{50}$, não é exagero supor que alguns dos requerimentos de Antônio Tristão tiveram de ser resolvidos pela própria arquiconfraria, como o caso da "fatura da ponte", obra fundamental para se aceder à igreja de Santo Antônio. Sabe-se, através da documentação consultada, que, durante todo século XIX, a responsabilidade pela manutenção do entorno da igreja ficou a cargo da arquiconfraria de São Francisco. Em 1833, por exemplo, o síndico João Alves Caldas lança nos livros de despesa a quantia despendida "que paguei aos pretos que consertaram o caminho" 51 . Ainda no fim do século XIX, a arquiconfraria responsabilizava-se pela limpeza e manutenção do largo de São Francisco, onde se localiza a igreja de Santo Antônio e, até mesmo do córrego, que, por ali, passa, como se vê em outra despesa, do ano de 1890 , no valor de $1 \$ 880$ gastos "na limpeza do rego" e na "limpeza do largo" 52 .

\footnotetext{
${ }^{49}$ ANASTASIA, Carla Maria Junho. Conflitos de jurisdição e violência nos sertões da comarca do rio das mortes. Poliéia: História e Sociedade. Periódicos UESB, v. 2, n. 1, p.195, 2002. Disponível em: http://periodicos.uesb.br/index.php/politeia/issue/archive

${ }^{50}$ Este tópico e melhor desenvolvido por: FRAGOSO, João; BICALHO, Maria Fernanda Baptista; GOUVÊIA, Maria de Fátima Silva. (org.). O antigo regime nos trópicos: a dinâmica imperial portuguesa (séculos XVI-XVIII). Rio de Janeiro: Civilização Brasileira, 2001.

${ }^{51}$ APSB - ASF. Livro 1 Doc. 162.

${ }^{52}$ APSB - ASF. Livro 8 Doc. 4009
}

\begin{tabular}{l|ll|l} 
VOL. 3 & N. 5 & JAN/UN. 2017
\end{tabular} 


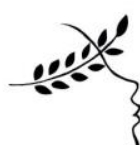

$\left\{\right.$ FACES DE CLIO $\begin{array}{l}\text { REVISTA DISCENTE DO PROGRAMA DE } \\ \text { PÓS-GRADUAÇÃO EM HISTÓRIA - UFJF }\end{array} \begin{array}{r}\text { ISSN } \\ 2359-4489\end{array}$

Vê-se que os anos iniciais de atuação da arquiconfraria coincidem com os primeiros passos autônomos da vila de São Bento, recém-separada de São José del-Rei. A fundação da arquiconfraria de São Francisco parece ter movimentado o desenvolvimento de Tamanduá, pois, mesmo que os requerimentos de Antônio Tristão Barbosa não tenham sido atendidos, não é arriscado supor que esses assuntos já haviam sido discutidos junto à municipalidade antes de serem formalizados em requerimentos remetidos ao governo em Lisboa. Comparada à antiga vila de São José, Tamanduá ainda avançava em seu desenvolvimento urbano. Em correspondência de 1798, mapeada por Cláudia Damasceno Fonseca, a câmara de São João delRei afirmava que "Queluz, Barbacena e Tamanduá são Vilas, e nem têm chafarizes nem calçadas as ruas" ${ }^{53}$, o que mostra que a vila ainda necessitava, nesse período, de obras estruturais.

Como se nota, a vila de São Bento do Tamanduá compunha-se de um grande termo, com sua população distribuída em fazendas e uma pequena parte habitando na vila, composta em maioria de comerciantes, prestadores de serviços, escravos e a elite dos "homens bons", responsável pela administração da câmara. Essa população diversificada irá compor os anos iniciais da vila e das associações religiosas leigas então existentes no lugar.

Através das fontes disponíveis, observa-se também que o processo de urbanização da vila mostrava-se interconectado com o mundo rural e que os limites entre vila e fazenda não eram muito precisos. Cumpre notar que as implementações eclesiásticas, realizadas tanto na construção de edificações religiosas quanto na delimitação dos limites das freguesias, serviam como uma importante referência ao desenvolvimento urbano das antigas vilas mineiras.

As edificações religiosas, além de comporem de modo bastante característico as vilas e arraiais mineiros, funcionavam como singular espaço de sociabilidade. Locais esses que eram alvos tanto de interesses em comum quanto de conflitos por poder e ocupação, como é possível observar nos requerimentos feitos por Antônio Tristão Barbosa, quando solicitava a Sua Majestade licença para poder utilizar do templo sede da Arquiconfraria de São Francisco.

\footnotetext{
${ }^{53}$ FONSECA. p.367.
}

\begin{tabular}{l|lll|l} 
VOL. 3 & N. 5 & JAN/JUN. 2017
\end{tabular}




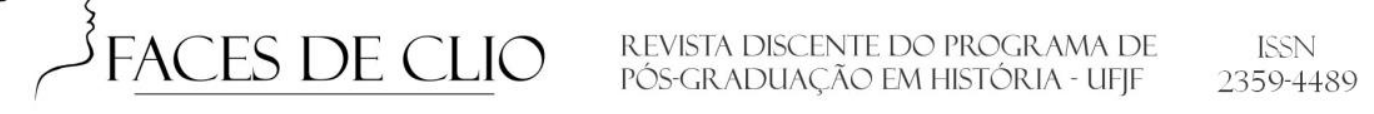

Dessa maneira, este artigo buscou, através do estudo do caso de São Bento do Tamanduá, discutir como se operava o decurso do desenvolvimento urbano mineiro, no final do século XVIII e princípios do século XIX, tento em conta a complexidade do fenômeno e sua inter-relação com inúmeras outras variáveis, partindo, preferencialmente, da documentação eclesiástica, uma vez observada suas particulares possibilidades de análise.

\section{Abreviaturas}

APSB - Arquivo Paróquia de São Bento, Itapecerica, MG:

AHU - Arquivo Histórico Ultramarino, Lisboa, Portugal.

AEAM - Arquivo Eclesiástico da Arquidiocese de Mariana, Mariana, MG.

\section{Referências bibliográficas}

ANASTASIA, Carla Maria Junho. Conflitos de jurisdição e violência nos sertões da comarca do rio das mortes. Poliéia: História e Sociedade. Periódicos UESB, v. 2, n. 1, p.195, 2002. Disponível em: http://periodicos.uesb.br/index.php/politeia/issue/archive

ANDRADE, Francisco Eduardo de: A Invenção das Minas Gerais - empresas, descobrimentos e entradas nos sertões do Ouro da América Portuguesa. Belo Horizonte: Autêntica editora: Editora PUC Minas, 2008.

ÁVILA, Affonso (org). Barroco Mineiro: Glossário de Arquitetura e Ornamentação. Belo Horizonte: Fundação João Pinheiro, 1980.

BOSCHI, Caio César. O Barroco Mineiro: Artes e Trabalho - Coleção Tudo é História. São Paulo: Editora Brasiliense, 1988.

\begin{tabular}{l|ll|l} 
VOL. 3 & N. 5 & JAN/UN. 2017
\end{tabular}




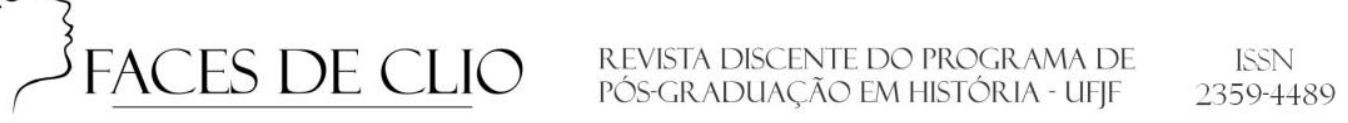

BOSCHI, Caio César. Os Leigos e o Poder (Irmandades Leigas e Política Colonizadora em Minas Gerais). São Paulo: Editora Ática, 1986.

BOXER, C. R. O império maritimo português 1415-182. São Paulo: Companhia das Letras, 2002.

CAMPOS, Adalgisa Arantes. Arte Sacra no Brasil Colonial. Belo Horizonte: C/Arte, 2011.

CAMPOS, Adalgisa Arantes. Introdução ao Barroco Mineiro. Belo Horizonte: Crisálida, 2006.

FERREIRA, Monsenhor Pedro Gondin; MOREIRA, Dom Gil Antônio. (org.). Semana Santa em Itapecerica - Ritual do Setenário. Divinópolis: Gráfica Sidil, 1996.

FONSECA, Cláudia Damasceno. Arraiais e Vilas D'el Rei - Espaço e Poder nas Minas Setecentistas. Belo Horizonte: Editora UFMG, 2011.

FONSECA, Gustavo Oliveira. Produção artística no centro-oeste mineiro nos séculos XVIII e XIX - Estudo sobre a igreja de Santo Antônio da Arquiconfraria de São Francisco em Itapecerica. Dissertação (mestrado em História). UFSJ, 2014. 263f.

FONSECA, Gustavo Oliveira. Artistas e artífices: a arte no centro-oeste mineiro nos séculos XVIII e XIX e a igreja de São Francisco em Itapecerica. In: CORGOZINHO, Batistina M. de Souza; FERREIRA, José Heleno; ARRUDA, Lucia M. Silva. (Org.). História e Memória do Centro-Oeste Mineiro: Perspectivas - Volume 4: Cidades Centenárias: desenvolvimento regional e inclusão social. Belo Horizonte: Editora O Lutador, 2013. Pág.111-122.

FRAGOSO, João; BICALHO, Maria Fernanda Baptista; GOUVÊIA, Maria de Fátima Silva. (org.). O antigo regime nos trópicos: a dinâmica imperial portuguesa (séculos XVI-XVIII). Rio de Janeiro: Civilização Brasileira, 2001.GEERTZ, Clifford. A interpretação das culturas. São Paulo: LCT, 1989.

\begin{tabular}{l|lll} 
VOL. 3 & N.5 & IAN/JUN. 2017
\end{tabular}




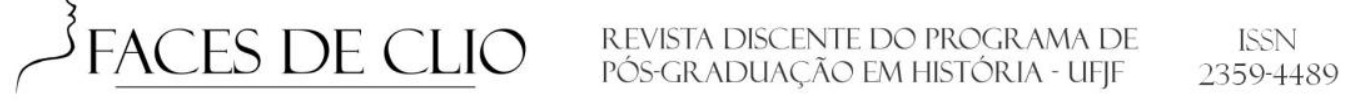

GRAMMONT, Guiomar de. Aleijadinho e o aeroplano. Rio de Janeiro: Civilização Brasileira, 2008.

JEUDY, Henri-Pierre. Espelho das Cidades. Rio de Janeiro: Casa da Palavra, 2005

KOSELLECK, Reinhart. Futuro passado: contribuição à semântica dos tempos históricos. Rio de Janeiro: Ed. PUC-Rio / Contraponto, 2006.

MOREIRA, Dom Gil Antônio. Itapecerica, sua fé sua música: História Eclesiástica de Itapecerica - MG. Belo Horizonte: Imprensa Oficial do Estado de Minas Gerais, 1984.

MOREIRA, Dom Gil Antônio. Matriz de São Bento - Cem anos de Bençãos. Itu: Ottoni Editora, 2005.

OLIVEIRA, Myriam A. R. de: O rococó religioso no Brasil e seus antecedentes europeus. São Paulo: Cosac \& Naify, 2003.

SAINT-HILAIRE, Auguste de. Viagem às nascentes do Rio São Francisco. Belo Horizonte: Ed. Itatiaia, 2004.

SERRÃO, Vítor. A Cripto-História da Arte: Análise de obras de arte inexistentes. Lisboa: Livros Horizonte, 2001.

SOUZA, Melina Teixeira. O reinado de Itapecerica no século XX: distintos sentidos de tradição. Dissertação (Mestrado em História). UFOP, 2012. 209f.

TRINDADE, Frei José da Santíssima. Visitas Pastorais de Dom Frei José da Santíssima Trindade (1821-1825). Belo Horizonte: Centro de Estudos Históricos e Culturais/Fundação João Pinheiro/IEPHA, 1998 .

\begin{tabular}{l|lll|} 
VOL. 3 & N. 5 & JAN/JUN. 2017
\end{tabular}




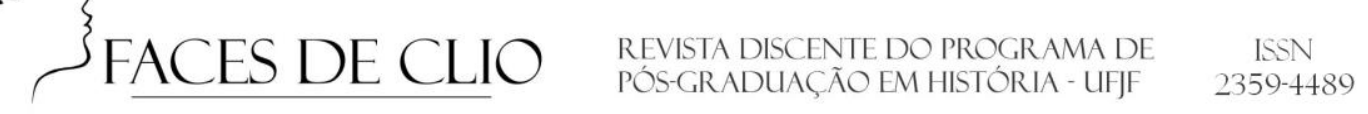

VASCONCELOS, Diogo de. História Antiga das Minas Gerais. Rio de Janeiro: Imprensa Nacional, 1948. Vol.1. Pág. 203.

VASCONCELOS, Diogo Pereira Ribeiro de. Breve descrição geográfica, física e política da capitania de Minas Gerais. Belo Horizonte: Centro de Estudos Históricos e Culturais/Fundação João Pinheiro, 1994.

VASCONCELLOS, Sylvio de. A arquitetura Colonial Mineira. In: ÁVILA, Affonso. Barroco: Teoria e Análise. São Paulo: Editora Perspectiva, 1997. Pág. 358. 